Arq. Bras. Med. Vet. Zootec., v.62, n.4, p.985-988, 2010

\title{
Comunicação
}

[Communication]

\section{Mastite bovina por Pasteurella multocida: estudo de nove casos}

\author{
[Bovine mastitis by Pasteurella multocida: a study of nine cases]
}

\author{
M.G. Ribeiro, G.H.B. Lara, M.C. Fernandes, A.C. Paes, R.G. Motta, \\ A.K. Siqueira, T. Salerno, F.J.P. Listoni
}

Faculdade de Medicina Veterinária e Zootecnia - UNESP

Caixa Postal 560

18618-000 - Botucatu, SP

\begin{abstract}
A mastite bovina é reconhecida como a principal enfermidade em animais de exploração leiteira, devido à redução na produção e na qualidade do leite, a gastos com tratamentos e honorários veterinários, ao descarte prematuro e à morte ocasional de animais, assim como ao potencial zoonótico dos agentes causais (Santos e Fonseca, 2007). As infecções da glândula mamária em vacas possuem etiologia complexa, causadas predominantemente por microrganismos de origem bacteriana e, em menor frequência, fungos, vírus e algas (Ribeiro, 2008). A mastite por Pasteurella multocida é considerada incomum. Os animais acometidos apresentam mastite clínica grave, hiperaguda ou aguda, podendo evoluir para agalaxia nos quatro quartos mamários, fibrose e atrofia do parênquima mamário. Ocasionalmente, os animais mostram sinais sistêmicos que incluem febre, taquicardia e dificuldade respiratória. O úbere se mostra edemaciado, e o leite proveniente dos quartos afetados apresenta coloração anormal, com presença de grumos, flocos e aspecto aquoso. Ademais, os bezerros de fêmeas com mastite por $P$. multocida podem desenvolver pneumonia fatal pelo consumo de leite contaminado (Radostits et al., 2007).
\end{abstract}

A principal forma de infecção mamária por $P$. multocida em vacas decorre da veiculação do patógeno a partir da microbiota da orofaringe dos bezerros, via ascendente pelo canal do teto, durante o ato de mamar. A pasteurelose mamária pode ocorrer também por disseminação linfo-hemática da bactéria das vias áreas superiores ou inferiores para o tecido glandular, ou ingressar pelo canal do teto, a partir do ambiente ou utensílios de ordenha contaminados (Radostits et al., 2007; Salerno et al., 2008).

No tratamento antimicrobiano das afecções por $P$. multocida em bovinos, incluindo na casuística de mastite, recomendam-se como princípios ativos: tetraciclinas, penicilina G, sulfonamidas/ trimetoprim, florfenicol, gentamicina, estreptomicina e enrofloxacina. Recentemente temse observado a preocupação com a multirresistência de linhagens de $P$. multocida isoladas de animais domésticos com mastite (Radostits et al., 2007). O presente estudo investigou nove casos de mastite bovina por $P$. multocida, com ênfase aos achados clínico-epidemiológicos e a ocorrência de multirresistência dos isolados aos antimicrobianos comumente indicados na terapia da mastite.

Durante o período de 2004 a 2008, foram encaminhados ao Serviço de Diagnóstico de Mastite em Animais da FMVZ-UNESP/Botucatu, SP, 4188 amostras de leite de vacas com mastite clínica ou subclínica, provenientes de propriedades rurais do interior dos estados de São Paulo e Minas Gerais. Todas as amostras de leite foram semeadas em ágar sangue bovino desfibrinado (5\%) e ágar MacConkey, incubadas em aerobiose, a $37^{\circ} \mathrm{C}$, por 72h. P. multocida foi classificada com base nas características morfo-tintoriais, de cultivo e bioquímicas (Quinn et al., 1994). O perfil de sensibilidade microbiana foi fundamentado na técnica de difusão com discos (Bauer et al., 1966; Performance..., 2003), utilizando princípios ativos recomendados na terapia intramamária ou parenteral da mastite bovina, a saber: amoxacilina $(10 \mu \mathrm{g})$, ampicilina $(10 \mu \mathrm{g})$, cefoperazona sódica 
$(75 \mu \mathrm{g})$, ceftiofur $(30 \mu \mathrm{g})$, gentamicina $(10 \mu \mathrm{g})$, oxacilina $(1 \mu \mathrm{g})$, penicilina/novobiocina $(40 \mu \mathrm{g})$, sulfadiazina/trimetoprim $(25 \mu \mathrm{g})$ e tetraciclina $(30 \mu \mathrm{g})$. A multirresistência aos antimicrobianos foi considerada nos isolados que apresentaram resistência simultânea a três ou mais fármacos.

Das 4188 amostras de leite submetidas ao cultivo microbiano, nove $(0,21 \%)$ apresentaram colônias brilhantes, não hemolíticas, de aspecto arredondado e tonalidade acinzentada em cultura pura no meio de ágar sangue, entre 24 e 48 horas de incubação. Não foi obtido isolamento no meio de MacConkey. Os exames bioquímicos revelaram microrganismos catalase, sacarose, oxidase e indol positivos, e urease e maltose negativos, que permitiram classificar os isolados como P. multocida (Quinn et al., 1994). O perfil de sensibilidade microbiana in vitro mostrou que a associação entre penicilina/novobiocina $(85,7 \%)$ foi a mais efetiva frente aos nove isolados, enquanto os demais fármacos apresentaram eficácia abaixo de 70,0\%. Os maiores índices de resistência das estirpes (Tab. 1) foram observados para tetraciclina $(57,1 \%)$, gentamicina $(33,4 \%)$, oxacilina $(33,4 \%)$, sulfadiazina/trimetoprim $(28,6 \%)$ e ceftiofur $(28,6 \%)$. Resistência múltipla a três ou mais antimicrobianos foi evidenciada em quatro $(44,4 \%)$ linhagens, particularmente com o uso de tetraciclina e gentamicina.

Tabela 1. Sensibilidade microbiana in vitro na prova de difusão com discos em nove linhagens de Pasteurella multocida isoladas em mastite bovina

\begin{tabular}{|c|c|c|c|}
\hline & Sensível & Parcialmente sensível & Resistente \\
\hline Antimicrobiano & $\begin{array}{c}\mathrm{n}^{\mathrm{o}} \text { de linhagens } \\
\text { sensíveis / } \mathrm{n}^{\mathrm{o}} \text { total de } \\
\text { isolados }(\%)\end{array}$ & $\begin{array}{c}\mathrm{n}^{\circ} \text { de linhagens } \\
\text { parcialmente } \\
\text { sensíveis / } \mathrm{n}^{\mathrm{o}} \text { total de } \\
\text { isolados }(\%)\end{array}$ & $\begin{array}{l}\mathrm{n}^{\mathrm{o}} \text { de linhagens } \\
\text { resistentes / } \mathrm{n}^{\mathrm{o}} \text { total } \\
\text { de isolados }(\%)\end{array}$ \\
\hline Amoxacilina & $3 / 5(60,0)$ & $1 / 5(20,0)$ & $1 / 5(20,0)$ \\
\hline Ampicilina & $4 / 7(57,1)$ & $2 / 7(28,6)$ & $1 / 7(14,3)$ \\
\hline Cefoperazona & $6 / 9(66,6)$ & $1 / 9(11,2)$ & $2 / 9(22,2)$ \\
\hline Ceftiofur & $4 / 7(57,1)$ & $1 / 7(14,3)$ & $2 / 7(28,6)$ \\
\hline Gentamicina & $4 / 9(44,4)$ & $2 / 9(22,2)$ & $3 / 9(33,4)$ \\
\hline Oxacilina & $4 / 9(44,4)$ & $2 / 9(22,2)$ & $3 / 9(33,4)$ \\
\hline Penicilina/novobiocina & $6 / 7(85,7)$ & $0 / 7(--)$ & $1 / 7(14,3)$ \\
\hline Sulfadiazina/Trimetoprim & $3 / 7(42,8)$ & $2 / 7(28,6)$ & $2 / 7(28,6)$ \\
\hline Tetraciclina & $2 / 7(28,6)$ & $1 / 7(14,3)$ & $4 / 7(57,1)$ \\
\hline
\end{tabular}

Os nove animais com mastite por $P$. multocida eram provenientes de propriedades distintas, de diferentes raças ou mestiços, manejados em sistemas de ordenha manual ou mecânica. Destes, sete $(77,8 \%)$ mostravam sinais de mastite clínica, sem sinais respiratórios ou outros sistêmicos, e dois $(22,2 \%)$ mastite subclínica. O leite proveniente dos quartos com mastite clínica apresentava aspecto aquoso, de tonalidade amarelada, contendo ou não grumos. Dos nove animais, seis $(66,7 \%)$ eram ordenhados com bezerro ao pé. Em somente uma propriedade, havia histórico de transporte recente dos animais. Os isolamentos de P. multocida ocorreram ao longo de todo o ano.

Classicamente, a mastite bovina por $P$. multocida é considerada rara em diferentes países (Chanda et al., 1989; Radostits et al., 2007). No presente estudo, o cultivo microbiológico das amostras de leite revelou o microrganismo em somente nove animais $(0,21 \%)$, dos quais sete com mastite clínica e dois com mastite subclínica. De maneira similar, a lactocultura de 702 amostras de vacas com mastite no Brasil revelou $P$. multocida em somente 1,25\% da amostragem (Langoni et al., 1991). A etiologia de 7.902 amostras de leite de vacas com mastite clínica e 850 subclínicas no país verificou também a baixa participação de $P$. multocida na casuística da mastite bovina em, respectivamente, $0,60 \%$ e $0,38 \%$ das amostras de leite clínicas e subclínicas (Langoni, 1995). A despeito da baixa ocorrência de $P$. multocida na gênese da mastite bovina, a pasteurelose mamária em vacas ocorre geralmente sob a forma clínica grave. Nos nove animais 
estudados, sete $(77,8 \%)$ apresentavam mastite clínica, com presença de edema, hiperemia e sensibilidade dolorosa do úbere, além de secreção láctea de coloração alterada, aspecto aquoso, contendo grumos. Estes achados estão em consonância com outros autores, que também assinalaram o predomínio da forma clínica grave na pasteurelose mamária em vacas (Chanda et al., 1989; Radostits et al., 2007).

As manifestações respiratórias, septicêmicas ou mesmo neurológicas por $P$. multocida em bovinos estão intimamente relacionadas com fatores imunossupressivos, incluindo deficiências nutricionais, extremos ou variações bruscas de temperatura, condições estressantes no transporte dos animais e participação recente em feiras, exposições ou outros eventos de aglomeração de animais (Smith, 1993; Lima et al., 2000; Salerno et al., 2008). Contrariamente, nas nove vacas reportadas com mastite por $P$. multocida, em somente uma foi constatado histórico de transporte recente, sugerindo que os fatores imunossupressivos notoriamente observados nas infecções sistêmicas pelo microrganismo em bovinos possuem menor impacto na pasteurelose mamária.

Postula-se que a principal forma de transmissão de $P$. multocida para a glândula mamária em vacas decorreria da veiculação do microrganismo a partir da microbiota oral dos bezerros no momento da amamentação. Secundariamente, a infecção mamária poderia ocorrer como sequela da disseminação do patógeno da nasofaringe das vacas ou de afecções pulmonares e, menos frequentemente, por contaminação ascendente do teto devido ao ambiente e utensílios de ordenha (Smith, 1993; Radostits et al., 2007; Salerno et al., 2008). Nas nove vacas estudadas, seis
$(66,7 \%)$ eram ordenhadas com bezerros ao pé, reforçando que a amamentação dos bezerros parece ser determinante na pasteurelose mamária em vacas, mediante a transmissão do microrganismo da microbiota da orofaringe dos bezerros para a glândula mamária. Ademais, nenhuma das vacas apresentava sinais respiratórios, sugerindo menor relevância da pasteurelose mamária, secundária à disseminação sistêmica do patógeno de infecções pulmonares.

O perfil de sensibilidade microbiana dos nove isolados revelou baixa eficiência in vitro de antimicrobianos amplamente utilizados na rotina da terapia de mastite em vacas. Foi constatada também multirresistência das linhagens em $44,4 \%$ frente aos antimicrobianos utilizados, especialmente com o uso de tetraciclina e gentamicina. Curiosamente, estes fármacos são indicados na terapia da pasteurelose bovina. A resistência múltipla aos antimicrobianos dos nove isolados de $P$. multocida, também destacada por outros autores (Chanda et al., 1989; Radostits et al., 2007), pode encontrar justificativa no uso indevido de fármacos no tratamento da mastite e outras afecções em vacas, que aumenta a pressão seletiva para linhagens multirresistentes (Ribeiro, 2008). Tal achado é preocupante, visto que os casos de pasteurelose mamária ocorrem predominantemente sob a forma de manifestações clínicas graves, necessitando de diagnóstico precoce e tratamento emergencial, com respaldo dos testes in vitro de sensibilidade microbiana, com vistas a melhorar a eficácia da terapia e minimizar os agravos ao tecido mamário por $P$. multocida.

Palavras-chave: vaca, mastite, Pasteurella multocida, multirresistência

\begin{abstract}
The uncommon occurrence of bovine mastitis by Pasteurella multocida is reported in nine cows. Mammary pasteurellosis was predominantly diagnosed predominantly in clinical cases, in dairy cows milked in the presence of calves. Low interference of immunosuppressive or predispose factors and absence of pulmonary signs were observed in animals. In vitro multiple drug resistance of isolates was observed to three or more conventional antimicrobials, especially with use of tetracycline and gentamicin. Epidemiologic findings, clinical signs, and antimicrobial profile were discussed in nine cases of bovine mastitis caused by $\mathrm{P}$. multocida.
\end{abstract}

Keywords: cow, mastitis, Pasteurella multocida, multiple drug resistance 


\section{REFERÊNCIAS BIBLIOGRÁFICAS}

BAUER, A.W.; KIRBY, W.M.M.; SHERRIS, J.C. et al. Antibiotic susceptibility testing by a standardized single disk method. Am. J. Clin. Pathol., v.45, p.493-496, 1966.

CHANDA, A.; MUKHERJEE, K.S.; ROY, C.R. Clinical mastitis with Pasteurella multocida infection. Ind. Vet. J., v.66, p.571-572, 1989.

LANGONI, H. Etiologia da mastite bovina subclínica e clínica: perfil de sensibilidade microbiana, controle e repercussão na produção leiteira e na saúde pública, 1995. 200f. Tese (Livre Docência) - Faculdade de Medicina Veterinária e Zootecnia - Universidade Estadual Paulista, Botucatu.

LANGONI, H.; PINTO, M.P.; DOMINGUES P.F. et al. Etiologia e sensibilidade bacteriana da mastite bovina subclínica. Arq. Bras. Med. Vet. Zootec., v.43, p.507-15, 1991.

LIMA, K.C.; NARDI JUNIOR, G.; RIBEIRO, M.G. et al. Encefalite bovina por Pasteurella multocida. Relato de caso. Arq. Inst. Biol., v.67, p.135-138, 2000.

PERFORMANCE Standards for Antimicrobial Disk Susceptibility Test. 8.ed. Pennsylvania: CLSI-NCCLS, 2003.
QUINN, P.J.; CARTER, M.E.; MARKEY, B. et al. Clinical veterinary microbiology. London: Wolfe, 1994. 648p.

RADOSTITS, O.M.; GAY, C.C.; HINCHCLIFF, $\mathrm{K} . \mathrm{W}$. et al. (Eds). Veterinary medicine: A textbook of the diseases of cattle, horses, sheep, pigs, and goats. 10.ed. Philadelphia: Saunders, 2007. p.724-725.

RIBEIRO, M.G. Princípios terapêuticos na mastite em animais de produção e de companhia. In: ANDRADE, S.F. (Ed). Manual de terapêutica veterinária. 3.ed. Roca: São Paulo, 2008. p.759-771.

SALERNO, T.; SIQUEIRA, A.K.; FLAMÍNIO, A.P. et al. Pasteurelose bovina e ovina: Revisão de Literatura. Rev. Med. Vet., p.6-13, 2008.

SANTOS, M.V.; FONSECA, L.F.L. (Eds). Estratégias para controle de mastite e melhoria da qualidade do leite. São Paulo: Manole, 2007. 314p.

SMITH, B.P. Tratado de medicina interna de grandes animais. São Paulo: Manole, 1993. $1053 p$. 